\title{
Influence of the Level of the Carbon Source on the Autolysis of Aspergillus niger
}

\author{
By R. LAHOZ AND MAGDALENA MIRALLES \\ Instituto 'Jaime Ferrán' de Microbiologia, del Consejo Superior de \\ Investigaciones Científicas, Joaquín Costa 32, Madrid-6, Spain \\ (Accepted for publication 21 April 1970) \\ SUMMARY
}

The degree of autolysis of Aspergillus niger cultures grown and autolysed on $2.5,5,10,20$ and $40 \mathrm{~g}$./1. initial glucose was $64,60,43,43$ and $43 \%$, respectively. The greatest loss $(73 \%)$ of mycelial nitrogen took place with the lowest initial concentration of glucose. The greatest disappearance of lipids occurred in the period up to the 8th day of autolysis irrespective of the initial sugar concentration. The percentage loss of lipids was practically constant for the first four concentrations of initial glucose assayed. The amount of total free reducing substances contained in the mycelium at the beginning of the autolytic phase increased rapidly to a high level if the initial concentration of glucose was $40 \mathrm{~g}$. $/ 1$., but not if it was $20 \mathrm{~g}$./1. or less. The total mycelial carbohydrates determined by the anthrone reaction declined continuously irrespective of the initial sugar concentration. The percentage of mycelial constituents released during autolysis increased with initial concentration of glucose.

\section{INTRODUCTION}

The influence of certain imposed conditions on the autolytic phase of growth in cultures of filamentous fungi has been studied by Behr (I930), who was the first to describe the influence of the two types of media, physiologically acid and alkaline, upon different aspects of the autolytic phase of growth in cultures of Aspergillus niger. The effect of the addition of certain growth factors upon the autolytic processes of several filamentous fungi was investigated by Ritter (I955). Tandon \& Chandra (I962) studied the nature of the changes induced in autolysing cultures of Colletotrichum gloeosporioides by the addition of antibiotics. Changes in the general pattern of autolysis brought about by a variety of different cultural conditions in A. flavus and in A. terreus were described by Lahoz (I967), Lahoz, Reyes \& Beltrá (I966), Lahoz, Reyes, Beltrá \& Garcia-Tapia (1967) and Lahoz \& Gonzalez Ibeas (1968). In our search through the literature on the filamentous fungi we were unable to find any report of the effect of alteration of concentration of carbon source upon autolysis. The present work analyses the effect on autolysis of $A$. niger cultures of changes in the initial amounts of glucose.

\section{METHODS}

Organism. We used Aspergillus niger van Tieghem no. I 20.49 from the Centraalbureau voor Schimmelcultures, Baarn, Holland.

Chemicals. Mineral salts used in the preparation of culture media were of analytical 
grade from Probus S.A., Barcelona, Spain. Organic reagents were of analytical purity either from the British Drug Houses Ltd, Poole, Dorset, England, or from Sigma Chemical Co., St Louis, Mo., U.S.A.

Conditions of culture. Jena conical flasks (300 ml.), each containing $80 \mathrm{ml}$. of Czapek-Dox medium (g. /1. distilled water: $\mathrm{NaNO}_{3}, 2 ; \mathrm{KCl}, 0.5 ; \mathrm{KH}_{2} \mathrm{PO}_{4}, \mathrm{I} ; \mathrm{FeSO}_{4}$. ${ }_{7} \mathrm{H}_{2} \mathrm{O}, 0.0 \mathrm{I} ; \mathrm{MgSO}_{4} .7 \mathrm{H}_{2} \mathrm{O}, 0.5$ ) with glucose (anhydrous) at $2.5,5,10,20$ and $40 \mathrm{~g} . / 1$, were prepared and sterilized as previously described (Lahoz et al. 1966, 1967). At convenient intervals sets of 80 , 100 or 200 flasks were in turn inoculated with I or $2 \mathrm{ml}$. of a spore suspension of Aspergillus niger prepared as previously described (Lahoz et al. 1966, 1967). Each batch was incubated on a reciprocating shaker at 90 oscillations/min. with an amplitude of $10 \mathrm{~cm}$. at 24 to $26^{\circ}$ in the dark. At the time of the maximum yield of mycelium at least five flasks were withdrawn from the shaker; the number of flasks taken at any particular time depended on the amount of mycelium present when harvesting. In the set containing the lowest glucose concentration samples of IO, I5 or 20 flasks had to be taken and their contents combined since growth was very scanty. During the later periods 45 flasks were needed to give sufficient mycelium for detailed analysis. In all cases the mycelium was filtered free of culture fluid, washed with water and dried at $70^{\circ}$ to constant weight. The culture fluid was discarded after the residual glucose and the $\mathrm{pH}$ had been estimated.

Analytical methods. Total nitrogen, carbohydrates and lipids in mycelium were determined as in previous work (Lahoz et al. 1966, I967, 1968). Methods of extraction of total free reducing substances from defatted mycelium and their estimation were as previously described (Lahoz et al. 1966, 1967; Lahoz \& Gonzalez Ibeas, 1968; Lahoz, Beltrá \& Ballesteros, 1970). The alkali soluble protein from the residue was determined by the method of Lowry, Rosebrough, Farr \& Randall (I95I) using hot $\left(80^{\circ}\right)$ $\mathrm{N}-\mathrm{NaOH}$ (IOO mg. mycelium/25 ml. $\mathrm{NaOH}$ ) extracts.

\section{RESULTS}

The highest yield of mycelium was attained at the $3 \mathrm{rd}, 3 \mathrm{rd}, 4^{\text {th }}, 7^{\text {th }}$ and $\mathrm{II}$ th day of incubation for media containing $2 \cdot 5,5$, Io, 20 and $40 \mathrm{~g}$./l. initial glucose, respectively. As in previous work, the loss in mycelial dry weight was adopted as a criterion of autolysis. Therefore the day that the maximum amount of mycelium formed in the different concentrations tested was taken as the 'zero day of autolysis' and samples to be analysed were withdrawn from the shaker $8,23,38$ and 53 days later.

The loss of weight in autolysing mycelium of Aspergillus niger grown at different initial glucose concentrations can be seen in Table I. The percentage autolysis for the $2.5,5,10,20$ and $40 \mathrm{~g}$. $/ 1$. concentrations were $64,60,43,43$ and $43 \%$, respectively. Above ro g./l. the degree of autolysis remained uniformly low as the concentration of the carbon source increased.

The total nitrogen in the autolysing mycelium of Aspergillus niger is shown in Table 2. With each initial concentration of glucose the nitrogen content of the mycelium (expresssed as nitrogen/unit dry weight and as nitrogen/culture) at first diminished as the culture aged, but became practically constant later. The greatest loss $(73 \%)$ of mycelial nitrogen took place at the lowest initial glucose concentration (Table 3).

The greatest disappearance of lipids from autolysing mycelium of Aspergillus niger 
took place before the 8 th day of autolysis at all the initial glucose concentrations except $40 \mathrm{~g}$. glucose $/ 1$. at which the amount of fat in the mycelium remained constant throughout the whole period of autolysis (Table 4 ). The total fat lost during 38 days

Table I. Influence of initial glucose concentration on mycelial weight during autolysis of Aspergillus niger

\begin{tabular}{|c|c|c|c|c|c|}
\hline \multirow{2}{*}{$\begin{array}{c}\text { Initial } \\
\text { glucose } \\
\text { concentra- } \\
\text { tion (g./l.) }\end{array}$} & \multicolumn{5}{|c|}{ Time of autolysis (days) } \\
\hline & o & $\begin{array}{c}8 \\
\text { Weigh }\end{array}$ & $\begin{array}{c}23 \\
\text { celiu }\end{array}$ & $\begin{array}{l}38 \\
\text { (mg.) }\end{array}$ & 53 \\
\hline $2 \cdot 5$ & 76 & 43 & 33 & 30 & 27 \\
\hline 5 & I 50 & 86 & 72 & $6 I$ & 59 \\
\hline IO & 205 & I 40 & I 23 & II 6 & I 16 \\
\hline 20 & 409 & 276 & 252 & 238 & 232 \\
\hline 40 & 730 & 579 & 496 & 460 & 410 \\
\hline
\end{tabular}

Table 2. The effect of initial glucose concentration on the total nitrogen in autolysing mycelium of Aspergillus niger

\begin{tabular}{|c|c|c|c|c|c|c|c|c|c|c|}
\hline \multirow{3}{*}{$\begin{array}{c}\text { Initial } \\
\text { glucose } \\
\text { concen- } \\
\text { tration } \\
\text { (g./l.) }\end{array}$} & \multicolumn{10}{|c|}{ Time of autolysis (days) } \\
\hline & \multicolumn{2}{|c|}{0} & \multicolumn{2}{|c|}{8} & \multicolumn{2}{|c|}{23} & \multicolumn{2}{|c|}{38} & \multicolumn{2}{|c|}{53} \\
\hline & $A^{*}$ & $\mathrm{~B}+$ & A & $\mathrm{B}$ & A & B & A & B & A & B \\
\hline $2 \cdot 5$ & 4.5 & $3 \cdot 4$ & $3 \cdot 6$ & I $\cdot 5$ & $3 \cdot 3$ & $I \cdot I$ & $3 \cdot I$ & 0.9 & - & - \\
\hline 5 & $4 \cdot 9$ & $7 \cdot 3$ & 4.0 & $3 \cdot 4$ & $3 \cdot 7$ & $2 \cdot 6$ & $3 \cdot 7$ & $2 \cdot 3$ & - & - \\
\hline IO & $4 \cdot 0$ & $8 \cdot 2$ & $3 \cdot 5$ & 4.9 & $3 \cdot 4$ & $4 \cdot 2$ & $3 \cdot 2$ & $3 \cdot 7$ & $3 \cdot 3$ & $3 \cdot 8$ \\
\hline 20 & $3 \cdot 8$ & $15 \cdot 4$ & $3 \cdot 3$ & $9 \cdot I$ & $3 \cdot 1$ & $7 \cdot 7$ & $3 \cdot 0$ & $7 \cdot 3$ & 3.0 & $7 \cdot 0$ \\
\hline 40 & $2 \cdot 8$ & $20 \cdot 1$ & $2 \cdot 9$ & 16.5 & $2 \cdot 2$ & II $\cdot 0$ & $2: 4$ & $I I \cdot 2$ & $2 \cdot 5$ & $10 \cdot 3$ \\
\hline
\end{tabular}

Table 3. Percentage loss of mycelial nitrogen during the first 38 days of autolysis of Aspergillus niger at different initial glucose concentrations

$\begin{array}{ccccc}\begin{array}{c}\text { Initial } \\ \text { glucose } \\ \text { (g./1.) }\end{array} & \begin{array}{c}\text { Zero day } \\ \text { (mg./flask) }\end{array} & \begin{array}{c}\text { 38th day } \\ \text { (mg./flask) }\end{array} & \text { Difference } & \% \text { loss } \\ 2.5 & 3 \cdot 4 & 0.9 & 2 \cdot 5 & 73 \\ 5 & 7 \cdot 3 & 2 \cdot 3 & 5 \cdot 0 & 68 \\ \text { I0 } & 8 \cdot 2 & 3 \cdot 7 & 4 \cdot 5 & 54 \\ 20 & 15 \cdot 4 & 7 \cdot 3 & 8 \cdot 1 & 52 \\ 40 & 20 \cdot 1 & 11 \cdot 2 & 8 \cdot 9 & 44\end{array}$

Table 4. Influence of initial glucose concentration on the amount of fat in autolysing mycelium of Aspergillus niger

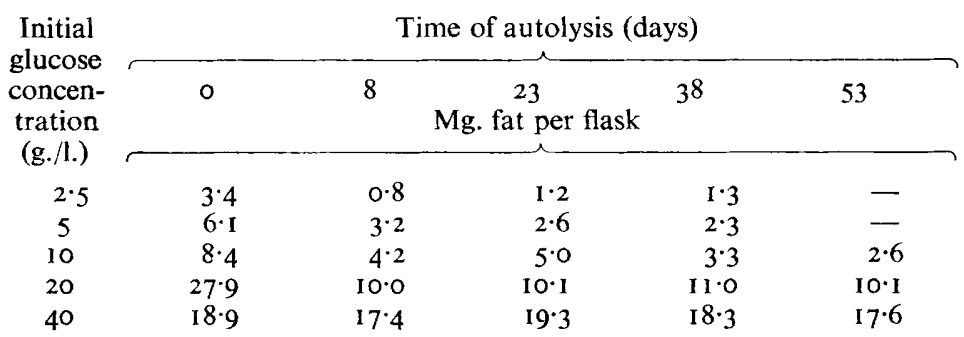




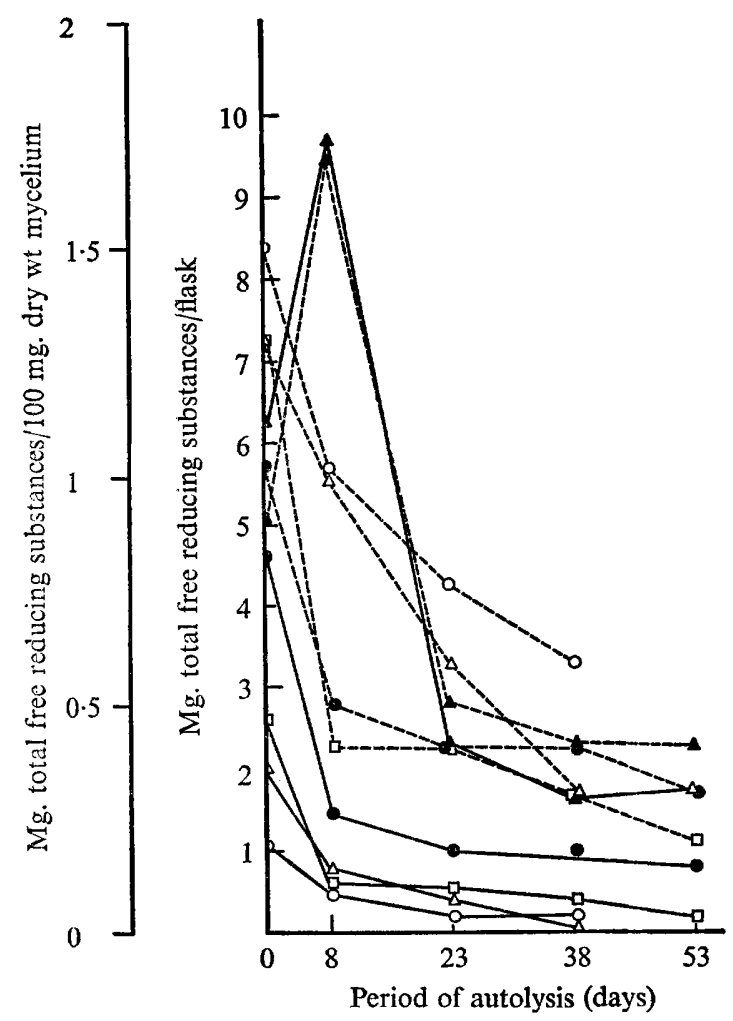

Fig. I. Influence of initial glucose concentration on free reducing substances in the mycelium during autolysis of Aspergillus niger cultures. Mg./ $100 \mathrm{mg}$. dry weight mycelium, - - - - -; mg./flask, —— $; 2.5$ g./l. glucose, $\bigcirc ; 5$ g./1. glucose, $\triangle ;$ I 0 g./l. glucose, $\square ; 20$ g./l. glucose, ; $40 \mathrm{~g}$./l. glucose, $\Delta$.

Table 5. Relation of total carbohydrates in autolysing mycelium of Aspergillus niger to initial glucose concentration

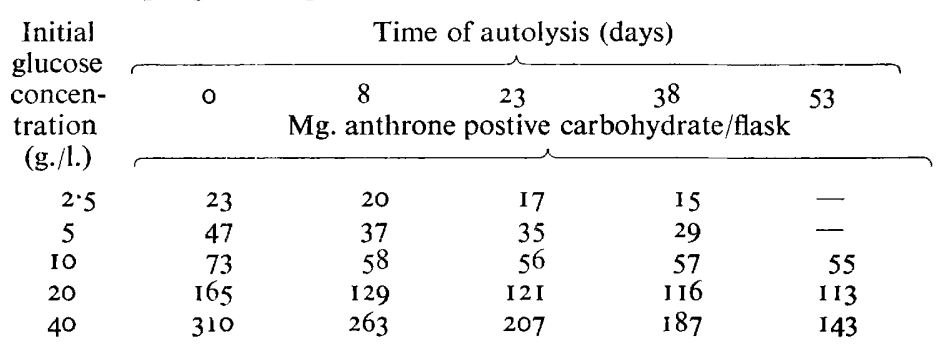

Table 6. Final balance sheet of the loss of partial cellular constituents from autolysing mycelium of Aspergillus niger in cultures with different initial glucose concentrations Initial concentration of glucose (g./1.)

mg./100 mg.

Total nitrogen

Crude fat

Total carbohydrates

Total loss (\%)

$\begin{array}{rrrrr}2.5 & 5 & \text { IO } & 20 & 40 \\ 5 \cdot 2 & 5 \cdot 5 & 5 \cdot 0 & 4 \cdot 7 & 3 \cdot 1 \\ 4 \cdot 2 & 4 \cdot 2 & 6 \cdot 5 & 1 \cdot 0 & - \\ 17 \cdot 0 & 19 \cdot 7 & 20 \cdot 1 & 29 \cdot 2 & 52 \cdot 1 \\ 26 \cdot 4 & 29 \cdot 4 & 31 \cdot 6 & 34.9 & 55 \cdot 2\end{array}$


of autolysis of $A$. niger, grown and autolysed at $2.5,5,10$ and $20 \mathrm{~g}$. glucose/1. was practically uniform at $61,62,60$ and $60 \%$ respectively. The change in total carbohydrates during autolysis can be seen in Table 5: they declined continuously at all of the initial glucose concentrations. The alkali soluble protein in the mycelium remained constant during autolysis for 53 days.

The percentage of the constituents released by autolysing cultures grown at different initial glucose levels increases with initial glucose concentration (Table 6).

\section{DISCUSSION}

Behr (1930), in his work on autolysis of Aspergillus niger, showed that the percentage of mycelial nitrogen continuously increases or remains constant with the ageing of the culture in physiologically alkaline media. It is shown here that the nitrogen in the mycelium decreased when expressed as N/100 mg. dry weight and N/flask (Table 2).

The increase in the content of the free reducing substances in mycelium during autolysis, which in previous work (Lahoz, 1967; Lahoz et al. 1970) has been attributed to an enzymic hydrolysis due to autolytic enzymes, is confirmed by the present work for the $40 \mathrm{~g}$. $/ 1$. level of initial glucose. The experiments showed that the initial concentration of the carbon source exerted a marked influence upon the behaviour of free reducing substances in the mycelium. A fall in free reducing substances with time was characteristic of all initial glucose levels except for the $40 \mathrm{~g} / \mathrm{l}$. (Fig. I).

Similarly, the quantitative changes in lipids (Table 4) in autolysing mycelium seemed to be related to the initial level of the carbon source. Lipids in autolysing mycelium of Aspergillus niger grown in the highest initial glucose concentration (40 g./1.) remained at a constant level. A similar constancy was observed while studying autolysis in still cultures of $A$. flavus, in which a concentration of 50 glucose/l. was used. On the other hand the change in the amount of the carbon source did not exert a noticeable influence on the behaviour of total carbohydrates contained in mycelium of $A$. niger during autolysis. The pattern of continuous diminution, as autolysis proceeds, has been found previously (Lahoz \& Gonzalez Ibeas, 1968; Lahoz et al. 1970).

The authors are indebted to Miss Teresa Raposo, who gave skilled technical assistance during the course of this work. This study is based on a portion of a thesis submitted by one of us (M. M.) in partial fulfilment of the requirements for the Ph.D. degree in the Faculty of Pharmacy, University of Madrid.

\section{REFERENCES}

BeHr, G. (1930). Über Autolyse bei Aspergillus niger. Archiv für Mikrobiologie, 4I8.

LAHOZ, R. (1967). Quantitative changes in the content of non-nitrogenous compounds during autolysis of Aspergillus terreus. Journal of General Microbiology 46, $45 \mathrm{I}$.

LAhoz, R., Beltrá, R. \& Ballesteros, A. M. (1970). Biochemical changes in cultures of Nectria galligena during the autolytic phase of growth. Annals of Botany 34, 205.

Lahoz, R. \& Gonzalez Ibeas, J. (1968). The autolysis of Aspergillus flavus in an alkaline medium. Journal of General Microbiology 53, IOI.

LAHOZ, R., ReYes, F. \& BeltrÁ, R. (I966). Some chemical changes in the mycelium of Aspergillus flavus during autolysis. Journal of General Microbiology 45, 4I.

Lahoz, R., Reyes, F., Beltrá, R. \& Garcia-Tapia, C. (1967). The autolysis of Aspergillus terreus in a physiologically acid medium. Journal of General Microbiology 49, 259. 
Lowry, O. H., Rosebrough, N. J., Farr, A. L. \& Randall, R. J. (195I). Protein measurement with the Folin phenol reagent. Journal of Biological Chemistry 193, 265.

RitTer, R. (1955). Physiologische Untersuchungen an Zygomyceten. Archiv für Mikrobiologie 22, 248.

Tandon, R. N. \& Chandra, S. (1962). Changes in amino acids, sugars and organic acids in the mycelium of Colletotrichum gloeosporioides Penz. during the autolytic phase of growth. Phyton. International Journal of Experimental Botany, Buenos Aires 19, 127. 